\title{
Alkaloid, Sterol and Triterpenoids from Glycosmis pentaphylla (Retz.) DC
}

\section{Iftekhar Ahmed ${ }^{1}$, Ridwan Islam¹, Md. Al Amin Sikder ${ }^{1}$, Mohammad Rashedul Haque $^{1}$, Md. Abdullah Al-Mansur ${ }^{2}$ and Mohammad A. Rashid ${ }^{1}$}

\author{
${ }^{1}$ Phytochemical Research Laboratory, Department of Pharmaceutical Chemistry, Faculty of Pharmacy, \\ University of Dhaka, Dhaka-1000, Bangladesh \\ ${ }^{2}$ Bangladesh Council of Scientific and Industrial Research (BCSIR), Dr. Qudrat-I-Khuda Road, \\ Dhanmondi, Dhaka-1205, Bangladesh
}

Received: May 21, 2014; Accepted: June 04, 2014; Published (web): July 06, 2014

\begin{abstract}
Four compounds were isolated from the methanol extract of leaves of Glycosmis pentaphylla. The structures of the isolated compounds were solved as epi-oleanolic acid (1), $\beta$-amyrin (2), spinasterol (3) and arborinine (4) by extensive spectroscopic studies, including high field NMR analyses as well as co-TLC with authentic samples. This appeares to be the first report of their occurrence from Glycosmis species.
\end{abstract}

Key words: Glycosmis pentaphylla, Rutaceae, epi-oleanolic acid, $\beta$-amyrin, spinasterol, arborinine

\section{INTRODUCTION}

Glycosmis pentaphylla (Retz.) DC (Bengali name- Motmoti/Daton; Family- Rutaceae) is a small evergreen tree or shrub which grows to a height of 5 metres and widely distributed in tropical forests at low altitudes in Bangladesh, India, China, Thailand, Malaysia, Indonesia and Phillipines. ${ }^{1}$ G. pentaphylla is a medicinal plant, various parts of which are used during confinement, in intestinal ailments, anaemia and jaundice. ${ }^{2}$ It was found to possess anti-pyretic, antimicrobial, anthelmintic, anti-inflammatory and cytotoxic activities. ${ }^{2-4}$ Previously alkaloids and diglycoside acyl esters have been isolated from the root and bark of this plant. ${ }^{5}$ Its stem has also been reported as a rich source of flavonoids, naphthoquinone and acridone alkaloids. As a part of our continuing studies with medicinal plants of Bangladesh, ${ }^{6,7}$ we investigated $G$. pentaphylla and we, herein, report epi-oleanolic acid (1), $\beta$-amyrin (2), spinasterol (3) and arborinine (4) from $G$. pentaphylla for the first time.

Correspondence to: Mohammad A. Rashid

Tel.: 880-2-9661900-73, Extn.-8137;

Fax: 880-2-9667222; E-mail: rashidma@du.ac.bd

Dhaka Univ. J. Pharm. Sci. 13(2): 115-118, 2014 (December)

\section{MATERIALS AND METHODS}

General. ${ }^{1} \mathrm{H}$ NMR spectra were acquired using Ultra Shield Bruker 400 NMR instrument using $\mathrm{CDCl}_{3}$ and the chemical shifts are reported in ppm with respect to TMS or residual non deuterated solvent signals.

Plant material. Leaves of G. pentaphylla were collected from National Botanical Garden, Dhaka, Bangladesh in March 2013. The plant was taxonomically identified at Bangladesh National Herbarium, Dhaka, where a voucher specimen has been deposited. The leaves were first sun dried and then ground into a coarse powder using a grinding machine.

Extraction and isolation. The powdered leaf (1 $\mathrm{kg}$ ) was soaked in $3.0 \mathrm{~L}$ of methanol for 7 days and then filtered through a cotton plug followed by Whatman filter paper number 1 . The extract was concentrated with a rotary evaporator and an aliquot $(10 \mathrm{~g})$ of the concentrated methanol extract was then subjected to vacuum liquid chromatography (VLC). ${ }^{8}$ The column was packed with silica gel (Kiesel gel $60 \mathrm{H})$ under vacuum and after application of sample, the column was eluted with pet-ether, followed by mixtures of pet-ether and ethyl acetate as well as 
ethyl acetate and methanol mixtures in order of increasing polarities to provide 25 fractions, each 100 $\mathrm{ml}$. Compound 1 was isolated as colorless gum from VLC fraction-5 of the methanol extract which was further purified by preparative thin layer chromatography (PTLC) using 1\% ethyl acetate in toluene, while by using the same solvent system for PTLC, compound $\mathbf{2}$, as a colorless mass and compound 4, as yellow gummy residue, were obtained from fraction- 8 and fraction- 3 , respectively.

A portion $(5 \mathrm{~g})$ of the concentrated methanol extract was fractionated by the modified Kupchan partitioning protocol into pet-ether $(0.65 \mathrm{~g})$, carbon tetrachloride $(0.55 \mathrm{~g})$, chloroform $(0.30 \mathrm{~g})$ and aqueous $(2.5 \mathrm{~g})$ soluble materials. The carbon tetrachloride soluble partitionate was chromatographed over silica gel (Kiesel gel 60H, mesh 70230) and the column was eluted with pet-ether followed by mixtures of pet-ether and ethyl acetate in order of increasing polarities. Compound $\mathbf{3}$ was obtained as white gum from the column fractions eluted with $10 \%$ ethyl acetate in pet-ether.

\section{Properties of isolated compounds}

Epi-oleanolic acid (1): colorless gum; ${ }^{1} \mathrm{H}$ NMR (400 MHz, $\left.\mathrm{CDCl}_{3}\right): \delta 0.63\left(3 \mathrm{H}, \mathrm{s}, \mathrm{H}_{3}-24\right), 0.75(3 \mathrm{H}$, s, $\left.\mathrm{H}_{3}-26\right), 0.81\left(6 \mathrm{H}, \mathrm{s}, \mathrm{H}_{3}-25, \mathrm{H}_{3}-29\right), 0.87$ (3H, s, H 30), 0.95 (3H, s, $\left.\mathrm{H}_{3}-23\right), 1.04$ (3H, s, $\left.\mathrm{H}_{3}-27\right), 3.41$ $(1 \mathrm{H}$, br. s, H-3) and $5.25(1 \mathrm{H}, \mathrm{t}, J=3.5 \mathrm{~Hz}, \mathrm{H}-12)$.

ק-amyrin (2): colorless mass; ${ }^{1} \mathrm{H}$ NMR (400 $\left.\mathrm{MHz}, \mathrm{CDCl}_{3}\right): \delta 0.75\left(3 \mathrm{H}, \mathrm{s}, \mathrm{H}_{3}-24\right), 0.83\left(3 \mathrm{H}, \mathrm{s}, \mathrm{H}_{3}-\right.$ 28), 0.85 ( $\left.3 \mathrm{H}, \mathrm{s}, \mathrm{H}_{3}-29\right), 0.85$ ( $\left.3 \mathrm{H}, \mathrm{s}, \mathrm{H}_{3}-30\right), 0.89$ (3H, s, $\left.\mathrm{H}_{3}-23\right), 0.98$ (3H, s, H-25), 0.98 (3H, s, H26), $1.02\left(3 \mathrm{H}, \mathrm{s}, \mathrm{H}_{3}-27\right), 3.21(1 \mathrm{H}, \mathrm{dd}, J=3.5 \mathrm{~Hz}, \mathrm{H}-$ $3)$ and $5.21(1 \mathrm{H}, \mathrm{d}, J=3.5 \mathrm{~Hz}, \mathrm{H}-12)$.

Spinasterol (3): colorless gum; ${ }^{1} \mathrm{H}$ NMR (400 $\left.\mathrm{MHz}, \mathrm{CDCl}_{3}\right): \delta 0.65\left(3 \mathrm{H}, \mathrm{s}, \mathrm{H}_{3}-18\right), 0.76\left(3 \mathrm{H}, \mathrm{s}, \mathrm{H}_{3}-\right.$ 19), $0.81\left(3 \mathrm{H}, \mathrm{d}, J=6.5 \mathrm{~Hz}, \mathrm{H}_{3}-21\right), 0.83(3 \mathrm{H}, \mathrm{t}, J=$ $\left.6.5 \mathrm{~Hz}, \mathrm{H}_{3}-29\right), 0.87$ (3H, d, J = $\left.6.0 \mathrm{~Hz}, \mathrm{H}_{3}-26\right), 0.95$ $\left(3 \mathrm{H}, \mathrm{d}, J=6.5 \mathrm{~Hz}, \mathrm{H}_{3}-27\right), 3.66(1 \mathrm{H}, \mathrm{m}, \mathrm{H}-3), 5.05$ $(1 \mathrm{H}, \mathrm{dd}, J=14.0,8.0, \mathrm{H}-22), 5.15(1 \mathrm{H}, \mathrm{dd}, J=14.0$, 8.0, H-23) and $5.16(1 \mathrm{H}, \mathrm{m}, \mathrm{H}-7)$.

Arborinine (4): yellow gum; ${ }^{1} \mathrm{H}$ NMR (400 $\left.\mathrm{MHz}, \mathrm{CDCl}_{3}\right): \delta 3.84(3 \mathrm{H}, \mathrm{s}, \mathrm{N}-10), 6.27(1 \mathrm{H}, \mathrm{s}, \mathrm{H}-$
4), $7.25(1 \mathrm{H}, \mathrm{d}, J=8.5 \mathrm{~Hz}, \mathrm{H}-7), 7.51(1 \mathrm{H}, \mathrm{d}, J=8.5$ $\mathrm{Hz}, \mathrm{H}-5), 7.73(1 \mathrm{H}, \mathrm{d}, J=8.5 \mathrm{~Hz}, \mathrm{H}-6), 8.45(1 \mathrm{H}$, $\mathrm{dd}, J=8.5,2.0 \mathrm{~Hz}, \mathrm{H}-8)$ and $14.50(1 \mathrm{H}, \mathrm{s}, \mathrm{H}-9) ;{ }^{13} \mathrm{C}$ NMR (100 MHz, $\left.\mathrm{CDCl}_{3}\right): \delta 156.1$ (C-1), 133.9 (C-2), 159.3 (C-3), 86.7 (C-4), 114.6 (C-5), 133.9 (C-6), 121.5 (C-7), 126.5 (C-8), 180.8 (C-9), 140.4 (C-11), 105.7 (C-12), 120.7 (C-13), 141.9 (C-14), 56.0 (C-2), $60.8(\mathrm{C}-3)$ and $34.0(\mathrm{~N}-\mathrm{Me})$.

\section{RESULTS AND DISCUSSION}

A total of four compounds were isolated from the methanol extract and its carbon tetrachloride soluble fraction of leaves of $G$. pentaphylla by repeated chromatographic separation by VLC followed by further purification by PTLC. The structures of the isolated compounds were solved by NMR data analysis.

The ${ }^{1} \mathrm{H}$ NMR spectrum of compound $\mathbf{1}$ displayed a one proton triplet $(J=3.5 \mathrm{~Hz})$ at $\delta 5.25$, which indicated the presence of an olefinic proton at C-12 in a pentacyclic triterpene skeleton. The spectrum exhibited a broad singlet of one proton intensity at $\delta$ 3.41 indicative of $\mathrm{H}-3$ of the triterpene nucleus. The ${ }^{1} \mathrm{H}$ NMR spectrum also showed a singlet of six proton intensity at $\delta \quad 0.81$ and five three-proton singlets at $\delta 0.95,0.63,0.75,1.04$ and 0.87 which were attributed to $\mathrm{H}_{3}-25 \& \mathrm{H}_{3}-29$ and $\mathrm{H}_{3}-23, \mathrm{H}_{3}-24$, $\mathrm{H}_{3}-26, \mathrm{H}_{3}-27$ and $\mathrm{H}_{3}-30$, respectively. These ${ }^{1} \mathrm{H}$ NMR spectral data of compound $\mathbf{1}$ were almost identical to those published for oleanolic acid..$^{9}$ The major difference between oleanolic acid and compound 1 was the coupling pattern observed for C3 proton. In compound 1, H-3 appeared as a weakly coupled singlet with a small width half $\left(\mathrm{W}_{1 / 2}\right)$ in contrast to a double doublet $(J=11.4,4.4 \mathrm{~Hz})$ in oleanolic acid.

This revealed that the hydroxyl group in compound 1 was $\alpha$-oriented and thus H-3 was at the beta $(\beta)$ position. On this basis, compound 1 was characterized as epi-oleanolic acid, the identity of which was further confirmed by comparison of its spectral data to that of epi-oleanolic $\operatorname{acid}^{10}$ as well as by co-HPTLC with authentic sample. 
The ${ }^{1} \mathrm{H}$ NMR spectrum of compound 2 showed the presence of eight methyl group resonances at $\delta 0.89$, $0.75,0.98,0.98,1.02,0.83,0.85(6 \mathrm{H})$ which could be assigned to $\mathrm{H}_{3}-23, \mathrm{H}_{3}-24, \mathrm{H}_{3}-25, \mathrm{H}_{3}-26, \mathrm{H}_{3}-27, \mathrm{H}_{3}$ $28, \mathrm{H}_{3}-29$ and $\mathrm{H}_{3}-30$, respectively of an oleananetype triterpenoid carbon skeleton. ${ }^{11} \mathrm{~A}$ characteristic triplet at $\delta 5.21(J=5.5 \mathrm{~Hz})$ was attributed to $\mathrm{H}-12$. This again suggested an olean-12-ene-type carbon skeleton. On the other hand, a one proton double

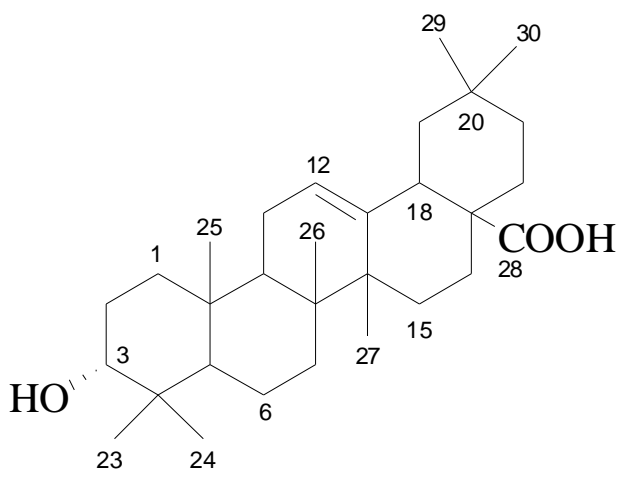

1

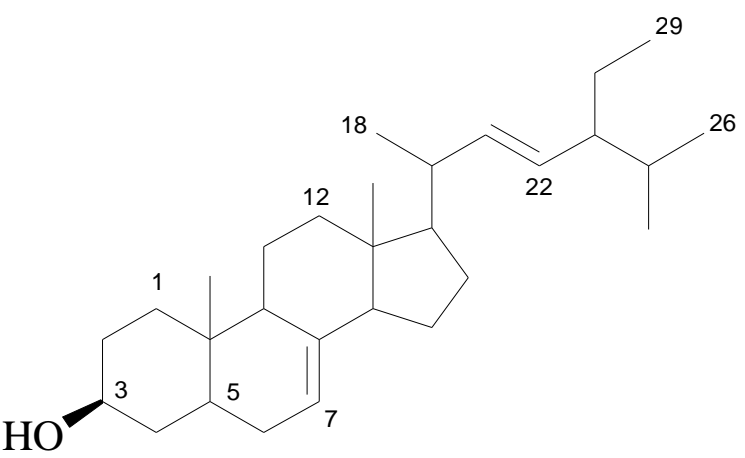

3

The ${ }^{1} \mathrm{H}$ NMR spectrum of compound $\mathbf{3}$ displayed signals for six methyl groups including two tertiary methyls as singlets at $\delta 0.65$ and 0.76 which could be assigned to Me-18 and Me-19, respectively. The signals of three secondary methyl groups were observed as doublets at $\delta 1.06(J=6.5 \mathrm{~Hz}), 0.87(J=$ $6.0 \mathrm{~Hz})$ and $0.95(J=6.5 \mathrm{~Hz})$ attributable to Me-21, Me-26 and Me-27, respectively. A three proton triplet at $\delta 0.83(J=6.5 \mathrm{~Hz})$ could be ascribed to the primary methyl group (Me-29). A total of three olefinic-proton resonances were observed at 5.05 $(1 \mathrm{H}, \mathrm{dd}, J=14.0,8.0, \mathrm{H}-22), 5.15$ (1H, dd, $J=14.0$, doublet at $\delta 3.21(1 \mathrm{H}, \mathrm{d}, J=11.5,3.5 \mathrm{~Hz})$ could be ascribed to the typical oxymethine proton at C-3 of the pentacyclic triterpene. The above spectral features are in close agreement to those observed for $\beta$ amyrin. Thus, compound $\mathbf{2}$ was characterized as $\beta$ amyrin. This identity was further confirmed by direct comparison of its ${ }^{1} \mathrm{H}$ NMR spectrum with that recorded for $\beta$-amyrin ${ }^{12}$ as well as by co-TLC with an authentic sample.

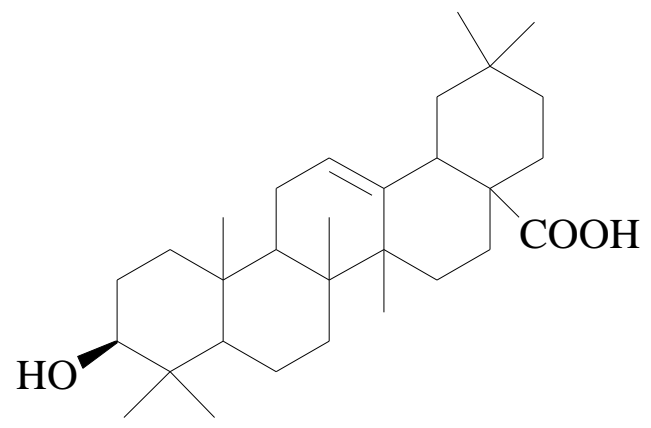

2

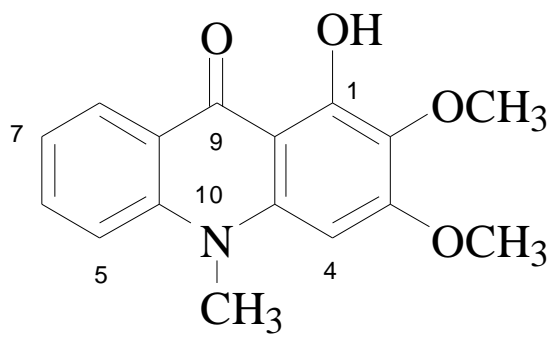

4

8.0, H-23), $5.16(\mathrm{~m})$ which were assigned to the trans-olefinic protons at C-22, C-23 and $\mathrm{H}-7$, respectively. The typical oxymethine proton in the steroidal compound was evident as a multiplet at $\delta$ 3.66 which could be accounted for H-3. On the basis of the above spectral data, compound $\mathbf{3}$ was characterized as spinasterol $^{13}$ which has been confirmed by co-TLC of compound $\mathbf{3}$ with a previously isolated authentic sample.

The ${ }^{13} \mathrm{C}$ NMR spectrum (100 $\mathrm{MHz}, \mathrm{CDCl}_{3}$ ) of compound 4 displayed a total of 16 carbon resonances, including an $\mathrm{N}-\mathrm{CH}_{3}$ signal at $\delta 34.1$ and a 
carbonyl group at $\delta$ 180.8. The DEPT spectrum indicated that out of the 16 carbons in compound 4, 8 had attached protons. The ${ }^{1} \mathrm{H}$ NMR spectrum (400 $\mathrm{MHz}, \mathrm{CDCl}_{3}$ ) of compound 4 revealed signals characteristic of a polycyclic acridone-type alkaloid, where two of the three hydroxyl groups were methylated $(\mathrm{OMe})$. It further displayed signal for a chelated hydroxyl group at $\delta 14.50$. The spectrum also showed a highly characteristic ABCD spin system with four aromatic proton resonances at $\delta$ $7.51,7.73,7.25$ and 8.45 , which could be assigned to four adjacent protons $\mathrm{H}-5, \mathrm{H}-6, \mathrm{H}-7$ and $\mathrm{H}-8$ on ring $\mathrm{C}$, respectively. The sharp singlet at $\delta 6.27$ was attributable to the aromatic proton at C-4 of ring A. On the other hand, the three proton singlet at $\delta 3.84$ could be assigned to $\mathrm{N}-\mathrm{CH}_{3}$. This was substantiated by the ${ }^{13} \mathrm{C}$ resonance at $\delta 34.1$. Two sharp singlets, each of three proton intensity, at $\delta 3.92$ and 4.01 were ascribed to two methoxyl groups. The ${ }^{13} \mathrm{C}$ NMR spectrum further showed two methoxyl carbons resonating at $\delta 56.0$ and 60.8 . The high field value at $\delta_{\mathrm{C}} 56.0$ was assigned to the sterically hindered methoxyl group at C-2, while that at 60.8 could be attributed to C-3 methoxyl group. The signal at $\delta$ 180.8 clearly showed that the C-9 position had a ketonic functionality. The above spectral features are in close agreement to those observed for arborinine. ${ }^{3}$ On this basis, the identity of compound 4 was established as arborinine. Again co-HPTLC with an authentic sample further confirmed the identification of compound $\mathbf{4}$ as arborinine.

\section{REFERENCES}

1. Faruque, M.O. and Uddin, S.B. 2014. Ethnomedicinal study of the Marma community of Bandarban district of Bangladesh. Aca. J. Med. Plants 2, 14-25.
2. Rahman, A.H.M.M., Biswas, M.C., Islam, A.K.M.R. and Zaman, A.T.M.N. 2013. Assessment of traditional medicinal plants used by local people of Monirampur Upazilla under Jessore district of Bangladesh. Wudpecker J. Med. Plants 2 , 99-109.

3. Rahmani, M., Muhammad, R. and Ali, A.M. 2010. Alkaloids and sulphur-containing amides from Glycosmis citrifolia and Glycosmis elongata. Sains Malaysiana 39, 445-451.

4. Jeeshna, M.V., Manorama, S. and Paulsamy, S. 2009. Antimicrobial properties of the medicinal shrub Glycosmis pentaphylla CORREA. J. Bas. App. Biol. 3, 25-27.

5. Ito, C., Kondo, Y., Rao, K.S., Tokuda, H., Nishino, H. and Furukawa, H. 1999. Chemical constituents of Glycosmis pentaphylla. Isolation of a novel naphthoquinone and a new acridone alkaloid. Chem. Pharm. Bull. 47, 1579-1581.

6. Hoque, T., Sikder, M.A., Kaisar, M.A., Chowdhury, A.A. and Rashid, M.A. 2011. Biological screening of two araceous plants growing in Bangladesh. Dhaka Univ. J. Pharm. Sci. 10, 131-135.

7. Sikder, M.A., Sharmin, T., Rahman, A.F.M.M., Haque, M.R., Rahman, M.S. and Rashid, M.A. 2013. Screening of four medicinal plants of Bangladesh for bioactivities. Dhaka Univ. J. Pharm. Sci. 12, 59-62.

8. Pelletier, S.W., Chokshi, H.P. and Desai, H.K. 1986. Separation of diterpenoid alkaloid mixtures using vacuum liquid chromatography. J. Nat. Prod. 49, 892-900.

9. Gohari, A.R., Saeidnia, S., Hadjiakhoondi, A., Abdoullahi, M. And Nezafati, M. 2009. Isolation and quantificative analysis of oleanolic acid from Satureja mutica Fisch. \& C. A. Mey. J. Med. Plants 8, 65-69.

10. Jung, M.J., Yoo, Y.C., Lee, K.B., Kim, J.B. and Song, K.S. 2004. Isolation of epi-oleanolic acid from Korean Mistletoe and its apoptosis inducing activity in tumor cells. Arch. Pharm. Res. 27, 840-844.

11. Bhatt, B. 2011. Chemical constituents of Solanum xanthocarpum. J. Chem. Pharm. Res. 3, 176-181.

12. Kushiro, T., Shibuya, M. and Ebizuka, Y. 1998. Cloning of oxidosqualene cyclase that catalyzes the formation of the most popular triterpene among higher plants. Eur. J. Biochem. 256, 238-244 .

13. Islam, R., Ahmed, I., Sikder, A.A., Haque, M.R., Al-Mansur, A., Ahmed, M., Rasheed, M. and Rashid, M.A. 2014. Chemical investigation of Mesua nagassarium (Burm. f.) Kosterm.J. Bas. App. Sci. 10, 124-128. 